\title{
Unilateral testicular degeneration in dogs: Effects on spermatozoal characteristics, testis and cauda epi- didymis
}

\author{
Chike Fidelis Oguejiofor*, Kenneth Orji Anya and Nnaemeka Kingsley Ogbanya \\ Department of Veterinary Obstetrics and Reproductive Diseases, Faculty of Veterinary Medicine, \\ University of Nigeria, Nsukka 410001, Nigeria \\ *Corresponding author: Chike Fidelis Oguejiofor, Email: chike.oguejiofor@unn.edu.ng
}

\begin{abstract}
Testicular degeneration is an important cause of poor fertility in dogs, but there is little knowledge on its effects on spermatozoa in affected dogs. The study investigated the specific effects of unilateral testicular degeneration (UTD) on spermatozoal characteristics in the testis and epididymis. Ten sexually mature Nigerian indigenous breed of dogs, comprising 5 normal dogs and 5 dogs with UTD were used for the study. The testis and epididymis were removed via orchidectomy for morphological and histopathological evaluation. Sperm in the testis and cauda epididymis were analysed. The samples were grouped into four as N1 (normal right testis), N2 (normal left testis), ND (non-degenerated testis in UTD dogs), and D (degenerated testis in UTD dogs). Data were analysed using one-way ANOVA. There were significant decreases $(p<0.001)$ in testes weight, length, width and volume, and the gonado-somatic index in the $\mathrm{D}$ testes compared to the contralateral ND and the $\mathrm{N}$ groups. The $\mathrm{D}$ group also had significantly lowered epididymal sperm total and progressive motility, viability and concentration $(p<0.001)$, and a decreased testicular sperm concentration $(p<0.01)$. Moreover, there was a decreased percentage $(p<0.001)$ of morphologically normal sperm, with increased prevalence of sperm abnormalities in the $\mathrm{D}$ group compared to the other groups. In comparison with the $\mathrm{N}$ groups, the ND group had a significantly lowered $(p<0.05)$ epididymal sperm progressive motility, with increased percentage $(p<0.01)$ of sperm with proximal cytoplasmic droplets and looped tails. The findings demonstrated that UTD in dogs adversely affected spermatozoa in the testis and cauda epididymis. There was also evidence of compromised spermatozoa in the epididymis contralateral to the degenerated testis.
\end{abstract}

Keywords: Canine; Epididymis; Spermatozoa; Testicular atrophy; Testicular degeneration 


\section{Introduction}

Dogs are mainly bred for companionship, showmanship, security, hunting, and to provide valuable source of income for breeders. In addition, the slaughter and consumption of dog meat is popular in some countries (Podberscek, 2009; Ehimiyein et al., 2014). Therefore, infertility is likely to cause significant economic losses in canine breeding.

The testis is the primary organ of reproduction in male animals and functions in spermatogenesis (sperm production) and steroidogenesis (testosterone production). Testicular degeneration (TD) is considered as one of the most common causes of poor semen quality and acquired infertility in male dogs (Fontbonne, 2011; Domingos and Salomão, 2011) with a prevalence of 15-58\% (Ortega-Pacheco et al., 2006; Câmara et al., 2014). Testicular degeneration involves deterioration in the structure of the testis with a consequent loss of testicular function (Turner, 2007). It may affect one testis (unilateral) or both testes (bilateral), involving parts of the testis or the whole testis. The seminiferous epithelium of the testis is highly susceptible to damage, with a wide variety of agents causing reversible or irreversible degeneration (Parkinson, 2001). Acute TD can result secondary to a known insult such as exposure of the testes to toxins, radiation, extreme scrotal temperature, scrotal trauma, autoimmune disease, certain nutritional deficiencies, and infection with pathogenic organisms (Turner, 2007; Obi et al., 2013). Idiopathic TD has no identifiable underlying cause and has also been reported in dogs (Rehm, 2000; Fontbonne, 2011).

Spermatozoa can be recovered from the cauda epididymis of dogs by percutaneous epididymal aspiration, following castration, or at post mortem; for use in the investigation of sperm quality and spermatozoal characteristics (Varesi et al, 2013; Chima et al., 2017; Bhanmeechao et al., 2018), and for artificial breeding of bitches (Wydooghe et al., 2016). Ejaculated semen comprises sperm from both testes as well as secretions of the accessory sex glands. Thus, while evaluation of the ejaculate is used to assess semen for fertility potential, it precludes the investigation of specific testis/epididymis-derived effects of testicular disorders, and their impact on spermatozoa.

A few studies reported adverse effects of various testicular disorders, including TD on testicular and sperm morphology (Ortega-Pacheco et al., 2006; Câmara et al., 2014). In addition to sperm morphology, several other sperm character- 
istics and parameters (e.g. motility, viability, concentration) are known to have major influence on the integrity, functionality and fertility potential of spermatozoa (Johnston et al., 2001; Robert et al., 2016; Kolster, 2018). However, there is little knowledge on the effect of TD on these sperm characteristics in the testis or epididymis of affected dogs. Therefore, the aim of the study was to investigate the effects of unilateral testicular degeneration (UTD) on spermatozoal characteristics in canine testis and epididymis.

\section{Materials and methods}

\section{Animals}

Ten sexually mature (9-12 months old) apparently healthy Nigerian indigenous breed of dogs comprising 5 normal dogs: $\mathrm{N}$ (both testes normal and present in the scrotum) and 5 dogs with UTD: one non-degenerated (ND) and one degenerated (D) scrotal testes, were used for the study. Only dogs with no other observed reproductive pathology during clinical examination, but with a presentation and history of progressive unilateral scrotal testicular atrophy were selected. Animal welfare was observed in accordance with the National Institute of Health's Guide for the Care and Use of Laboratory Animals (National Research Council, 2011), and the protocol was approved by the Research Ethics Committee of the Faculty of Veterinary Medicine (2016/10-173537). The animals had body weights ranging from $7.8-9.7 \mathrm{~kg}$. Following an elective request for castration, orchidectomy (open castration) was performed as previously described (Hassan and Hassan, 2003). The surgery was performed following premedication with atropine sulphate (Pauco Atropine ${ }^{\circledast}$, Jiangsu Huayang Pharmaceutical, Jiangsu, China) at $0.04 \mathrm{mg} / \mathrm{kg}$ b.w., IM and xylazine hydrochloride (AnaSed ${ }^{\circledR}$, Akorn, Lake Forest, IL, USA) at $0.5 \mathrm{mg} / \mathrm{kg}$ b.w., IM., and under general anaesthesia using ketamine hydrochloride $\left(\operatorname{Ketmin}^{\circledR}\right.$, Laborate, Panipat, India) at $5 \mathrm{mg} / \mathrm{kg}$ b.w., IM. Post-surgical pain was alleviated with tramadol hydrochloride (Tradyl $^{\circledR}$, PT Interbat, East Java, Indonesia) at 2.5 $\mathrm{mg} / \mathrm{kg}$ b.w., IM twice daily for four days. The recovered testis and epididymis were dissected, and then utilized for gross morphometry, histopathology and sperm analysis. Each testis/epididymis was considered as the experimental unit. Thus, the samples were grouped into four as N1 (normal right testis), N2 (normal left testis), ND (non-degenerated testis in UTD dogs), and D (degenerated testis in UTD dogs). 


\section{Morphological and histopathological evaluation}

The weights of testis and epididymis were measured using an electronic weighing scale (Ohaus, Pine Brook, NJ, USA). Testis length and width, and epididymal length were measured with a vernier calliper. Testes volume was measured by the water displacement method (Sakamoto et al., 2007). The gonado-somatic index (GSI, g/kg) was calculated by dividing the testis weight (g) by the body weight $(\mathrm{kg})$. Likewise, the epididymo-somatic index (ESI, g/kg) was calculated by dividing the epididymis weight $(\mathrm{g})$ by the body weight $(\mathrm{kg})$ (Omari et al., 2018).

Small portions of cauda epididymal and testicular tissues were immersed in Bouin's fixative solution for $24 \mathrm{~h}$ and then transferred to $70 \%$ ethanol until processing. Histopathological sections were prepared and stained with haematoxylin and eosin as previously described (Slaoui and Fiette, 2011). Sections were evaluated for histopathology under light microscopy (Figure 1A-D). Samples were designated as normal $(\mathrm{N})$ in the absence of testicular or epididymal histologic abnormalities. Testicular degeneration was confirmed based on the presence of characteristic histopathological features as previously described (Yuan and McEntee, 1987; McGavin and Zachary, 2007; Câmara et al., 2014). Samples with absence of spermatozoa (azoospermia) in the epididymides indicated severe testicular degeneration and were excluded from the study, as the aim was to investigate spermatozoal characteristics in the different groups.

\section{Epididymal and testicular sperm analyses}

Sperm evaluation was performed as previously described (Seed et al., 1996; World Health Organization, 2010). Sperm motility was determined using sperm diffusion in phosphate buffered saline (PBS; $\mathrm{pH} 7.4,37{ }^{\circ} \mathrm{C}$ ) from sectioned cauda epididymis. Sperm motility (\%) was determined at $\times 400$ using a phase-contrast microscope (Motic B3; Motic, Carlsbad, CA, USA) equipped with a stage slide warmer (TCS-100; Amscope, Ivrine, CA, USA) set at $37^{\circ} \mathrm{C}$. Sperm viability (\%) was evaluated using eosin-nigrosin vital staining, and sperm were categorized as live (unstained head) or dead (marked pink-stained head) under light microscopy at $\times 1000$ magnification. Sperm morphological abnormalities were evaluated using phase-contrast microscopy and eosin-nigrosin staining. All values in percentage were determined by examining 200 sperm cells across different fields in duplicates. Cauda epididymal and testicular sperm concen- 
trations were determined following cauda epididymal/testicular tissue homogenization in PBS, and counting of sperm cells using a haemocytometer (Weber, England). Total sperm count was expressed as the number of sperm per gram cauda epididymis, and per gram testis, respectively (Seed et al., 1996).

\section{Statistical analysis}

Data were analysed with the one-way analysis of variance (ANOVA) tool using GraphPad Prism version 6.01 (GraphPad Software, Inc.), and the results presented as Mean \pm standard deviation (SD). Significant differences between means were confirmed using Tukey's honestly significant difference post hoc test. Results were considered statistically significant when $p<0.05$.

\section{Results}

\section{Morphological evaluation of testis and epididymis}

The results of gross morphological evaluation of the testis and epididymis in normal dogs and UTD dogs were as shown in Table 1. UTD affected the right testis in two dogs and the left testis in three dogs. There were significant decreases $(p<0.001)$ in testes weight, length, width and volume, and the GSI in the D testes compared to the contralateral ND testes in UTD dogs, and also compared to the $\mathrm{N}$ testes in the normal dogs. However, these parameters did not differ $(p>0.05)$ between the ND and the $\mathrm{N}$ testes. In addition, there were no significant differences in epididymal weight and length, and the ESI in all the four groups. 
Table 1. Testis and epididymis morphological characteristics in dogs with normal testes and unilateral testicular degeneration (UTD).

\begin{tabular}{|c|c|c|c|c|}
\hline \multirow[b]{2}{*}{ Parameter } & \multicolumn{2}{|l|}{ Normal } & \multicolumn{2}{|l|}{ UTD } \\
\hline & N1 & N2 & ND & D \\
\hline Testis weight (g) & $7.74 \pm 0.34^{\mathrm{a}}$ & $7.80 \pm 0.28^{a}$ & $7.92 \pm 0.31^{\mathrm{a}}$ & $5.12 \pm 0.64^{b}$ \\
\hline Testis length (cm) & $2.78 \pm 0.04^{\mathrm{a}}$ & $2.76 \pm 0.04^{\mathrm{a}}$ & $2.83 \pm 0.09^{\mathrm{a}}$ & $2.01 \pm 0.15^{\mathrm{b}}$ \\
\hline Testis width $(\mathrm{cm})$ & $2.26 \pm 0.04^{\mathrm{a}}$ & $2.27 \pm 0.03^{\mathrm{a}}$ & $2.29 \pm 0.05^{\mathrm{a}}$ & $1.57 \pm 0.10^{\mathrm{b}}$ \\
\hline Testis volume $\left(\mathrm{cm}^{3}\right)$ & $7.13 \pm 0.18^{\mathrm{a}}$ & $7.14 \pm 0.19^{\mathrm{a}}$ & $7.21 \pm 0.21^{\mathrm{a}}$ & $4.47 \pm 0.53^{b}$ \\
\hline Epididymis weight (g) & $1.25 \pm 0.11$ & $1.23 \pm 0.08$ & $1.25 \pm 0.12$ & $1.19 \pm 0.09$ \\
\hline Epididymis length $(\mathrm{cm})$ & $4.81 \pm 0.05$ & $4.83 \pm 0.04$ & $4.81 \pm 0.06$ & $4.72 \pm 0.09$ \\
\hline $\begin{array}{l}\text { Gonado-somatic index } \\
(\mathrm{g} / \mathrm{kg})\end{array}$ & $0.89 \pm 0.01^{\mathrm{a}}$ & $0.90 \pm 0.02^{\mathrm{a}}$ & $0.88 \pm 0.05^{\mathrm{a}}$ & $0.56 \pm 0.02^{\mathrm{b}}$ \\
\hline $\begin{array}{l}\text { Epididymo -somatic index } \\
(\mathrm{g} / \mathrm{kg})\end{array}$ & $0.14 \pm 0.01$ & $0.14 \pm 0.00$ & $0.14 \pm 0.00$ & $0.13 \pm 0.01$ \\
\hline
\end{tabular}

\section{Histopathology of the testis and cauda epididymis}

Evidences of TD were observed (Figure 1B) and these included the presence of decreased seminiferous tubular diameter, reduced thickness of the seminiferous epithelium, and scanty presence of spermatogenic cells. The cauda epididymis of the degenerated testis (Figure 1D) showed evidence of regression of epididymal tubules with reduced tubular diameter, scanty or no presence of spermatozoa in the tubular lumen and increased inter-tubular connective tissue. 

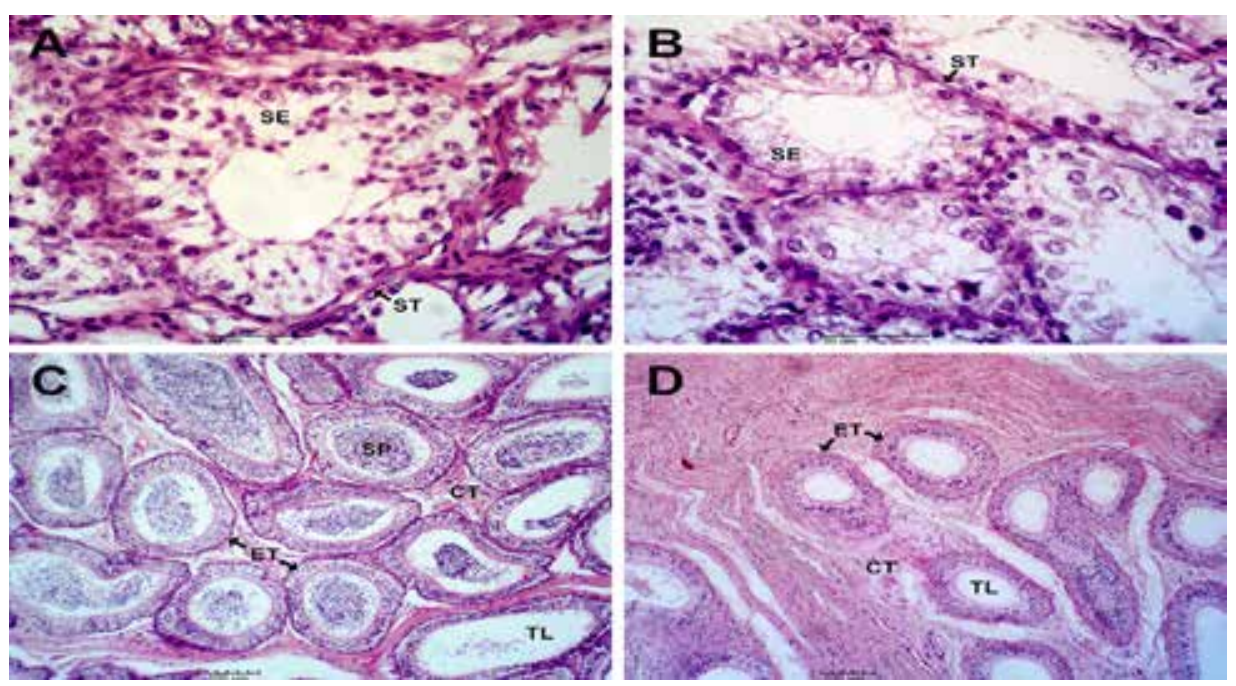

Figure 1. Histomicrographs of the testis and cauda epididymis in dogs with normal testes and unilateral testicular degeneration (UTD).

A: Normal testis showing large diameter of seminiferous tubules (ST), thick multi-layered and active seminiferous epithelium (SE) comprising numerous cells of the spermatogenic lineage. B: testis showing evidence of degeneration including decreased seminiferous tubular diameter, reduced thickness of the SE, and scanty presence of spermatogenic cells. C: Normal cauda epididymis showing large diameter of epididymal tubules (ET), presence of abundant spermatozoa (SP) in the tubular lumen (TL), scanty inter-tubular connective tissue (CT). D: cauda epididymis of degenerated testis showing regression of ET with reduced tubular diameter, scanty or no presence of SP in the TL and increased inter-tubular CT. (H \& E stain; scale bar: $50 \mu \mathrm{m}, 100 \mu \mathrm{m})$.

\section{Cauda epididymal and testicular sperm analysis}

The results of the cauda epididymal and testicular sperm analysis in normal dogs and UTD dogs are shown in Table 2 and Figure 2A-F. There were no significant differences $(p>0.05)$ in all the sperm parameters between the two $\mathrm{N}$ (N1 and N2) groups in the normal dogs. In comparison with the N groups, the ND group in dogs with UTD did not differ with respect to epididymal sperm total motility, viability and concentration, and testicular sperm concentration. However, they had a significantly lowered $(p<0.05)$ epididymal sperm progressive motility. The percentage of sperm with normal morphology and the prevalence of detached head, abnormal head, coiled midpiece (Dag defect) and coiled tail did not differ between the ND and N groups. However, there was increased 
percentage $(p<0.01)$ of sperm with proximal cytoplasmic droplets $(\mathrm{PCD})$ and looped tails in ND compared to the $\mathrm{N}$ groups.

Table 2. Cauda epididymis and testis spermatozoal characteristics in dogs with normal testes and unilateral testicular degeneration (UTD).

\begin{tabular}{lllll}
\hline Testis/Epididymis & \multicolumn{3}{l}{ Normal } & \multicolumn{2}{l}{ UTD } \\
\cline { 2 - 5 } & N1 & N2 & ND \\
\hline Epididymal sperm parameter (\%) & & & \\
Total motility & $83.6 \pm 2.7^{\mathrm{a}}$ & $84.8 \pm 3.0^{\mathrm{a}}$ & $81.3 \pm 5.7^{\mathrm{a}}$ & $11.5 \pm 9.1^{\mathrm{b}}$ \\
Progressive motility & $74.5 \pm 4.7^{\mathrm{a}}$ & $72.9 \pm 3.8^{\mathrm{a}}$ & $59.6 \pm 7.9^{\mathrm{b}}$ & $4.4 \pm 8.3^{\mathrm{c}}$ \\
Viability & $94.6 \pm 2.3^{\mathrm{a}}$ & $94.2 \pm 2.8^{\mathrm{a}}$ & $87.6 \pm 4.8^{\mathrm{a}}$ & $27.2 \pm 8.3^{\mathrm{b}}$ \\
Epididymal sperm morphology (\%) & & & \\
Normal sperm & $61.0 \pm 4.6^{\mathrm{a}}$ & $63.4 \pm 3.9^{\mathrm{a}}$ & $55.2 \pm 7.2^{\mathrm{a}}$ & $23.7 \pm 11.3^{\mathrm{b}}$ \\
Detached head & $4.1 \pm 1.5^{\mathrm{a}}$ & $3.7 \pm 1.1^{\mathrm{a}}$ & $4.8 \pm 2.8^{\mathrm{a}}$ & $13.7 \pm 4.2^{\mathrm{b}}$ \\
Abnormal head & $1.2 \pm 0.8^{\mathrm{a}}$ & $0.9 \pm 0.8^{\mathrm{a}}$ & $1.4 \pm 0.9^{\mathrm{a}}$ & $5.2 \pm 1.8^{\mathrm{b}}$ \\
Bent midpiece & $2.9 \pm 1.3$ & $3.2 \pm 0.9$ & $3.0 \pm 1.7$ & $6.5 \pm 4.1$ \\
Coiled midpiece/Dag defect & $0.8 \pm 0.8^{\mathrm{a}}$ & $0.6 \pm 0.9^{\mathrm{a}}$ & $0.8 \pm 1.1^{\mathrm{a}}$ & $4.8 \pm 2.5^{\mathrm{b}}$ \\
Proximal cytoplasmic droplets & $0.2 \pm 0.4^{\mathrm{a}}$ & $0.4 \pm 0.5^{\mathrm{a}}$ & $2.8 \pm 1.1^{\mathrm{b}}$ & $0.6 \pm 0.5^{\mathrm{a}}$ \\
Distal cytoplasmic droplets & $21.4 \pm 9.9$ & $19.6 \pm 10.8$ & $22.6 \pm 11.6$ & $27.4 \pm 16.5$ \\
Looped tail & $6.6 \pm 1.5^{\mathrm{a}}$ & $7.0 \pm 1.2^{\mathrm{a}}$ & $10.8 \pm 2.5^{\mathrm{b}}$ & $13.1 \pm 3.9^{\mathrm{b}}$ \\
Bent tail & $4.5 \pm 1.8$ & $4.1 \pm 1.6$ & $4.4 \pm 2.1$ & $4.6 \pm 2.5^{\mathrm{b}}$ \\
Coiled tail & $3.4 \pm 1.1^{\mathrm{a}}$ & $4.0 \pm 1.0^{\mathrm{a}}$ & $4.5 \pm 1.5^{\mathrm{a}}$ & $8.6 \pm 2.6^{\mathrm{b}}$ \\
Sperm concentration & & & & \\
Epididymis (x10 sperm/g) & $926.0 \pm 23.9^{\mathrm{a}}$ & $912.4 \pm 19.1^{\mathrm{a}}$ & $874.0 \pm 78.7^{\mathrm{a}}$ & $3.29 \pm 2.1^{\mathrm{b}}$ \\
Testis (x10 sperm/g) & $31.6 \pm 5.7^{\mathrm{a}}$ & $29.3 \pm 4.8^{\mathrm{a}}$ & $23.2 \pm 9.3^{\mathrm{a}}$ & $5.81 \pm 2.9^{\mathrm{b}}$ \\
\hline N1 (normal right testis); N2 (normal left testis); ND (non-degenerated testis in UTD dogs); D $($ degenerated \\
testis in UTD dogs). Values represent mean $\pm \mathrm{SD}$, n $=5$. Rows with different superscript letters indicate sig- \\
nificant differences between groups (P<0.05). & & & \\
& & &
\end{tabular}



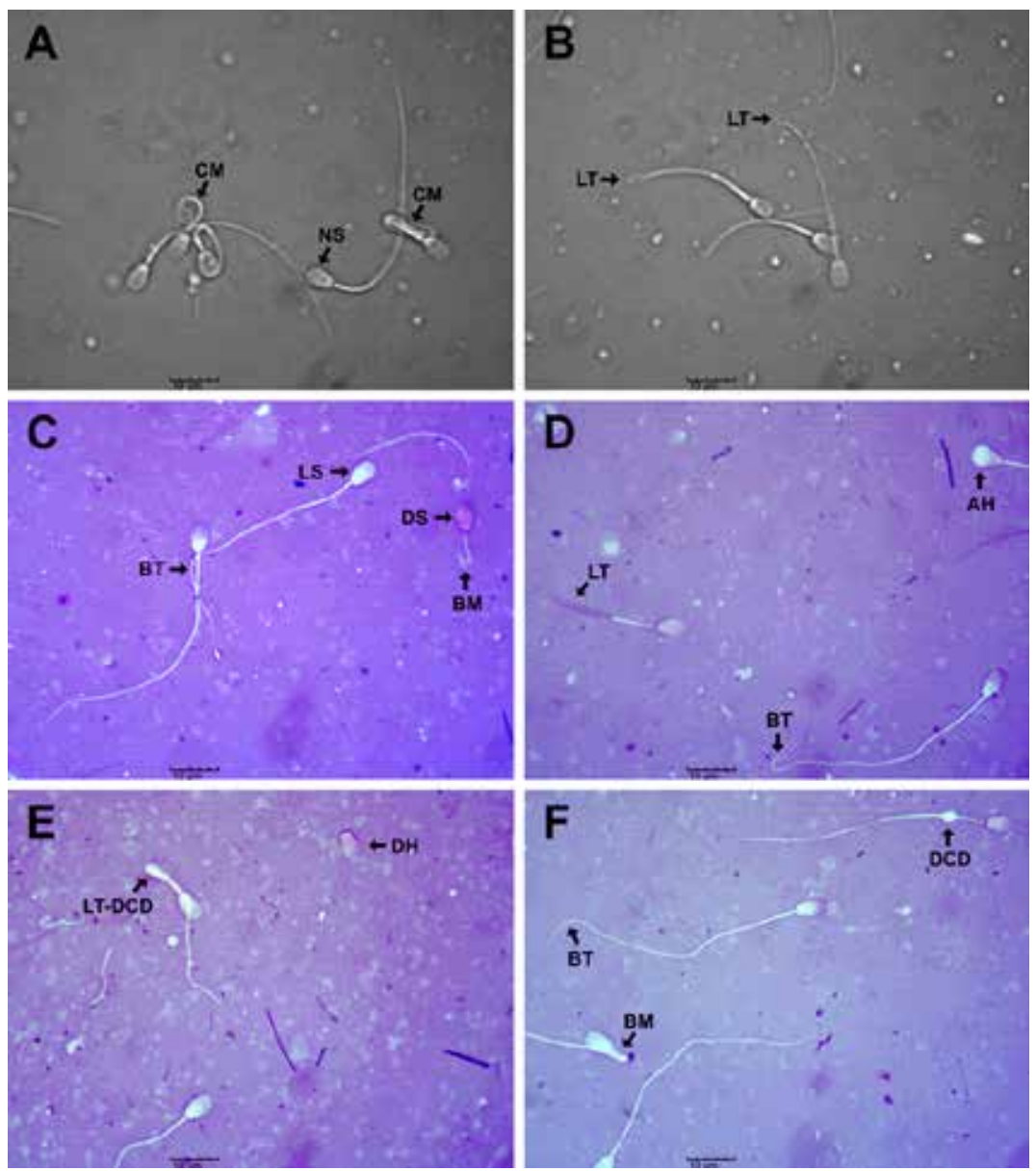

Figure 2. Micrographs of cauda epididymal sperm characteristics in dogs with normal testes and unilateral testicular degeneration (UTD).

A and B: Evaluation of sperm morphology using phase-contrast microscopy. Note the normal sperm (NS) and the presence of coiled midpiece (CM) or Dag defect and looped tail (LT) abnormalities. C-F: Evaluation of sperm viability and morphology using eosin-nigrosin staining. Note the live sperm (LS) and dead sperm (DS), and sperm with bent tail (BT), bent midpiece (BM), LT, pear-shaped abnormal head (AH), detached head (DH), looped tail enclosing a distal cytoplasmic droplet (LT-DCD), and distal cytoplasmic droplet (DCD) abnormalities. Scale bar $(10 \mu \mathrm{m})$.

On the other hand, there were significant differences in most of the observed sperm parameters in the D group in dogs with UTD, compared to the contralateral ND and the $\mathrm{N}$ groups. The $\mathrm{D}$ group had a significantly decreased $(p<0.001)$ 
epididymal sperm total and progressive motility, viability and concentration, compared to the other groups. Testicular sperm concentration was also significantly decreased in the D group compared to the contralateral ND $(p<0.01)$ and the $\mathrm{N}$ groups $(p<0.001)$. There was decreased percentage $(p<0.001)$ of normal sperm, and increased percentage of sperm with detached head $(p<0.001)$, abnormal head $(p<0.05)$, and coiled midpiece and coiled tail $(p<0.01)$ in the $\mathrm{D}$ group compared to the other groups. The percentage of sperm with looped tail was also increased in the $\mathrm{D}$ group $(p<0.01)$, but did not differ from the contralateral ND group. Out of all the observed sperm abnormalities, the percentage of sperm with bent midpiece, bent tail and distal cytoplasmic droplets (DCD) did not differ across all the groups.

\section{Discussion}

The study involved only dogs with a history of progressive unilateral testicular atrophy, and with histological evidence of TD and the presence of spermatozoa in the cauda epididymis. This differentiated the dogs from animals with testicular hypoplasia. Therefore, the selected animals were considered to be in a state of progressed TD but not in the advanced or terminal stage characterized by total loss of seminiferous epithelia and the absence of spermatozoa (azoospermia). We applied the term 'non-degenerated' rather than 'normal' in the contralateral ND group for two reasons. First, there were no specific information on the aetiologies of the TD, and to what extent they may have affected the contralateral testes. Second, we observed some sperm morphological abnormalities in the contralateral ND group compared to the normal dogs.

The results showed evidence of adverse effects of UTD in canine testes and spermatozoa. All the testicular gross morphological parameters (weight, length, width, volume and GSI) were markedly reduced following TD. This is consistent with other reports of a decline in testis size and weight in severe cases of TD or testicular atrophy in male animals (Parkinson, 2001; Ortega-Pacheco et al., 2006; Teankum et al., 2013). In contrast, epididymal weight and length and the ESI were not significantly altered by TD. This observation is also in agreement with previous reports of unaltered epididymal size or weight, concurrent with testicular atrophy in cases of TD or testicular atrophy in the stallion and boar (Blanchard and Varner, 1993; Teankum et al., 2013). Ortega-Pacheco et al. (2006) reported a decreased epididymal weight only in dogs with advanced TD but not partial TD, compared to the contralateral normal testes. 
The percentage motility and viability of cauda epididymal spermatozoa observed in this study for the $\mathrm{N}$ groups were comparable to the values reported previously in normal dogs (Chima et al., 2017; Bhanmeechao et al., 2018). Testicular degeneration decreased the epididymal sperm total and progressive motility in the D group. A low percentage of progressively motile sperm was also reported in the semen of stallions with TD (Blanchard et al., 2000). Decreased sperm motility may be related to abnormal sperm formation, and the observed increase in the proportion of sperm with morphologic abnormalities. Testicular degeneration also caused an increase in the percentage of dead epididymal sperm (decreased sperm viability) in the $\mathrm{D}$ group. This may be related to a disruption of the normal processes of spermatogenesis and sperm epididymal maturation, as a consequence of testicular insult and degeneration. Sperm motility is a critical indicator of normal structural and functional competence of spermatozoa, and there is positive correlation between the proportion of progressively motile sperm and sperm with normal morphology (Robert et al., 2016). Lowered fertility has been associated with $<70 \%$ total and progressive sperm motility and with increased proportion of dead sperm in the semen of dogs (Johnston et al., 2001; Oguejiofor, 2018).

The mean proportion of morphologically normal cauda epididymal sperm in the $\mathrm{N}$ groups in the study (62\%) was lower than the previous reports of $80 \%$ in epididymal sperm (Ortega-Pacheco et al., 2006) and $81 \%$ in vas deferens sperm (Câmara et al., 2014). This difference was attributed to the exclusion of epididymal sperm with DCD from the proportion of morphologically normal sperm in the study. However, Ortega-Pacheco et al. (2006) considered the presence of DCD as normal for sperm harvested from the cauda epididymis; a site for sperm maturation and storage. Although the proportion of sperm with DCD did not vary across the different groups, we observed a lower mean prevalence (21\%) in the $\mathrm{N}$ groups, in contrast to the $49 \%$ reported by that study (Ortega-Pacheco et al., 2006). A high prevalence (76\%) of total morphologically abnormal sperm was observed in the D group. Similarly, more than $80 \%$ cauda epididymal sperm abnormality was reported in cases of partial TD with oligospermia (Ortega-Pacheco et al., 2006). TD reduced the proportion of normal sperm in the study from $62 \%$ to $24 \%$. A decrease in normal sperm from $81 \%$ to $55 \%$ was also observed in vas deferens sperm of dogs with severe TD (Câmara et al., 2014). In addition, the findings here are consistent with the previous reports of a high prevalence of sperm with detached head abnormality (Ortega-Pacheco et al., 2006; Câmara et al., 2014), and other abnormalities 
including acrosomal defects, abnormal midpiece, and bent tails in severe TD (Ortega-Pacheco et al., 2006). Remarkably, these sperm defects are considered to have significant negative effect on canine fertility (Kolster, 2018).

Furthermore, TD decreased the testicular and cauda epididymal sperm concentrations. This may be a consequence of atrophy of the testicular parenchyma, degeneration of seminiferous epithelia, and decreased spermatogenesis. Since the cauda epididymis is the site of sperm storage, the lowered epididymal sperm concentration reflected a decrease in sperm production in the testis. Similarly, there was lowered daily sperm production per millilitre of testis and decreased sperm concentration in stallions with TD (Blanchard et al., 2001). Oligospermia and azoospermia may result in dogs with TD depending on the severity of the condition (Ortega-Pacheco et al., 2006; Fontbonne, 2011; Câmara et al., 2014). Lowered sperm numbers can lead to subfertility or infertility in affected dogs (Robert et al., 2016).

Interestingly, the findings suggest that TD in one testis may impair spermatozoa in the contralateral epididymis. In comparison with the $\mathrm{N}$ groups, the ND group had decreased sperm progressive motility and increased prevalence of PCD and looped tail sperm abnormalities. However, the mechanism for this impairment (whether direct or indirect) was unclear due to the unknown underlying cause of UTD in the affected dogs. Most of the sperm parameters were not significantly different between the $\mathrm{N}$ testes in normal dogs and the contralateral ND testis in UTD dogs. However, it is likely that the overall fertility outcome in dogs with UTD will depend on the progression and severity of TD. Extragonadal (epididymal) sperm reserve have been reported to positively correlate with gonadal sperm reserve and testicular weight (Ajani et al., 2015), and these in addition to testicular volume, were all significantly decreased by TD. Lowered testicular volume has also been associated with oligospermia and subfertility in males (Tijani et al., 2014). Taken together, TD caused decreased testicular and epididymal sperm concentration, decreased epididymal sperm motility, viability and concentration, and increased epididymal sperm abnormalities, and these defects can adversely affect fertility in dogs (Johnston et al., 2001; Robert et al., 2016; Kolster, 2018; Oguejiofor, 2018). 


\section{Conclusion}

The study demonstrated that UTD in dogs decreased testicular sperm concentration. It also adversely affected epididymal spermatozoal motility, viability, morphology, and sperm concentration in the testis and epididymis. Moreover, there was evidence of compromised spermatozoa (decreased sperm motility and increased sperm abnormalities) in the epididymis contralateral to the degenerated testis. These findings provide more information on alterations in sperm quality in relation to UTD. Although sperm cells may be recovered from the cauda epididymis of affected dogs for application in assisted reproductive technologies, further studies could investigate the functional capacity and fertilizing potential of such recovered spermatozoa.

\section{Conflict of interest}

The authors declare that there is no conflict of interest.

\section{References}

Ajani, O. S., Oyeyemi, M. O. and Moyinoluwa, O. J., 2015. Correlation between age, weight, scrotal circumference and the testicular and epididymal parameters of Red Sokoto bucks. J. Vet. Med. Anim. Health, 7, 159-163.

Bhanmeechao, C., Srisuwatanasagul, S., Prapaiwan, N. and Ponglowhapan, S., 2018. Reproductive aging in male dogs: the epididymal sperm defects and expression of androgen receptor in reproductive tissues. Theriogenology, 108, 74-80.

Blanchard, T. and Varner, D., 1993. Testicular degeneration. In: McKinnon, A. O. and Voss J. L. (Ed.), Equine Reproduction. Lea \& Febiger, Philadelphia, pp. 855-860.

Blanchard, T., Johnson, L. and Roser, A. J., 2000. Increased germ cell loss rates and poor semen quality in stallions with idiopathic testicular degeneration. J. Equine Vet. Sci., 20, 263-265.

Blanchard, T. L., Johnson, L., Varner, D. D., Rigby, S. L., Brinsko, S. P., Love, C. C. et al., 2001. Low daily sperm output per $\mathrm{ml}$ of testis as a diagnostic criteria for testicular degeneration in stallions. J. Equine Vet. Sci., 21, 33-35.

Câmara, L. B. R. M., Câmara, D. R., Maiorino, F. C., Silva Júnior, V. A. and Guerra, M. M. P., 2014. Canine testicular disorders and their influence on sperm morphology. Anim. Reprod., 11, 32-36. 
Chima, U., Abu, A., Dawuda, P., Kisani, A. and Ahemen, T., 2017. Effect of storage time on cauda epididymal sperm parameters of Nigerian local dogs. Open J. Vet. Med., 7, 151-161.

Domingos, T. C. S. and Salomão, M. C., 2011. Diagnostic tools of testicular disorders in dogs: review. Rev. Bras. Reprod. Anim., 35, 393-399.

Ehimiyein, A., Audu, S. and Ehimiyein, I., 2014. The role of dog trading and slaughter for meat in rabies epidemiology with special reference to Nigeria- a review. J. Exp. Biol. Agric. Sci., 2, 130-136.

Fontbonne, A., 2011. Infertility in male dogs: recent advances. Rev. Bras. Reprod. Anim., 35, 266-273.

Hassan, A. Z. and Hassan, F. B., 2003. An introduction to veterinary practice, Ahmadu Bello University Press Ltd., Zaria, Nigeria, pp. 288.

Johnston, S. D., Kustritz, M. V. R. and Olson, P. N. S., 2001. Semen collection, evaluation, and preservation. In: Johnston, S. D., Kustritz, M. V. R. and Olson P. N. S. (Ed.), Canine and Feline Theriogenology, $1^{\text {st }}$ edition, W. B. Saunders, Philadelphia, pp. 287-306.

Kolster, K. A., 2018. Evaluation of Canine Sperm and Management of Semen Disorders. Vet. Clin. Small. Anim., 48, 533-545.

McGavin, M. D. and Zachary, J. F., 2007. Pathologic Basis of Veterinary Disease, $4^{\text {th }}$ edition, Mosby Elsevier, Missouri, pp. 1476.

National Research Council, 2011. Guide for the Care and Use of Laboratory Animals, 8th edition, National Academies Press, Washington DC.

Obi, C. F., Obidike, R. I., Ezeh, I. O., Omoja, V. U., Iheagwam, C. N., Idika, I.K., et al., 2013. Effects of Trypanosoma brucei infection and diminazene aceturate therapy on testicular morphology and function of Nigerian local dogs. Vet. Parasitol., 196, $283-288$.

Oguejiofor, C. F., 2018. Sperm defects and infertility caused by bacterial infection of the reproductive tract in an adult male dog: A case report. Asian Pac. J. Reprod., 7, 236-238.

Omari, H., Al-Dawood, A. and Althenebat, A., 2018. Testicular and epididymal sperm reserve evaluations in three Jordanian goat breeds. J. Appl. Anim. Res., 46, 1522 1527.

Ortega-Pacheco, A., Rodríguez-Buenfil, J. C., Segura-Correa, J. C., Bolio-Gonzalez, M. E., Jiménez-Coello, M. and Linde Fosberg, C., 2006. Pathological conditions of the reproductive organs of male stray dogs in the tropics: prevalence, risk factors, 
morphological findings and testosterone concentration. Reprod. Domest. Anim., 41, 429-437.

Parkinson, T. J., 2001. Fertility and infertility in male animals. In: Noakes, D. E., Parkinson, T. J. and England G. C. W. (Ed.), Arthur's Veterinary Reproduction and Obstetrics, 3rd edition, Saunders, Edinburgh, UK, pp. 695-750.

Podberscek, A. L., 2009. Good to pet and eat: the keeping and consuming of dogs and cats in South Korea. J. Soc. Issues, 65, 615-632.

Rehm, S., 2000. Spontaneous testicular lesions in purpose-bred Beagle dogs. Toxicol. Pathol., 28, 782-787.

Robert, M. A., Jayaprakash, G., Pawshe, M., Tamilmani, T. and Sathiyabarathi, M., 2016. Collection and evaluation of canine semen- a review. Int. J. Sci. Environ. Tech., 5, 1586-1595.

Sakamoto, H., Saito, K., Oohta, M., Inoue, K., Ogawa, Y. and Yoshida, H., 2007. Testicular volume measurement: comparison of ultrasonography, orchidometry, and water displacement. Urology, 69, 152-157.

Seed, J., Chapin, R. E., Clegg, E. D., Dostal, L. A., Foote, R. H. and Hurtt, M. E., 1996. Methods for assessing sperm motility, morphology, and counts in the rat, rabbit, and dog: A consensus report. Reprod. Toxicol., 10, 237-244.

Slaoui, M. and Fiette, L., 2011. Histopathology procedures: from tissue sampling to histopathological evaluation. In: Gautier, J. C. (Ed.), Drug Safety Evaluation: Methods in Molecular Biology (Methods and Protocols), Humana Press, Totowa, New Jersey, pp. 69-82.

Teankum, K., Tummaruk, P., Kesdangsakonwut, S., Antarasena, T., Lacharoj, S., Singlor, J., et al., 2013. Testicular atrophy and its related changes in culled boars: a pathological investigation. Thai J. Vet. Med., 43, 511-518.

Tijani, K. H., Oyende, B. O., Awosanya, G. O., Ojewola, R. W. and Yusuf, A. O., 2014. Assessment of testicular volume: A comparison of fertile and sub-fertile West African men. Afr. J. Urol., 20, 136-140.

Turner, R. M. O., 2007. Pathogenesis, diagnosis, and management of testicular degeneration in stallions. Clin. Tech. Equine Pract., 6, 278-284.

Varesi, S., Vernocchi, V., Faustini, M. and Luvoni, G. C., 2013. Quality of canine spermatozoa retrieved by percutaneous epididymal sperm aspiration. J. Small Anim. Pract., 54, 87-91.

World Health Organization, 2010. WHO Laboratory Manual for the Examination and Processing of Human Semen, 5th edition, WHO Press, Geneva, Switzerland. 
Wydooghe, E., Snoeck, F. and Van Soom, A., 2016. Establishment of live birth following intravaginal artificial insemination with chilled epididymal dog semen collected post mortem: case report. In: Proceedings, International Symposium on Canine and Feline Reproduction (ISCFR), 22-25 June 2016, Paris, France, pp. 231.

Yuan, Y. D. and McEntee, K., 1987. Testicular Degeneration, Rat. In: Jones, T.C., Mohr, U. and Hunt R. D. (Ed.), Genital System. Monographs on Pathology of Laboratory Animals, Springer-Verlag, Berlin, pp. 212-218. 